Document downloaded from:

http://hdl.handle.net/10251/94466

This paper must be cited as:

Herrera Gamboa, MP.; Molines, J.; Medina, JR. (2016). Hydraulic stability of nominal and sacrificial toe berms for mound breakwaters on steep sea bottoms. Coastal Engineering. 114:361-368. doi:10.1016/j.coastaleng.2016.05.006

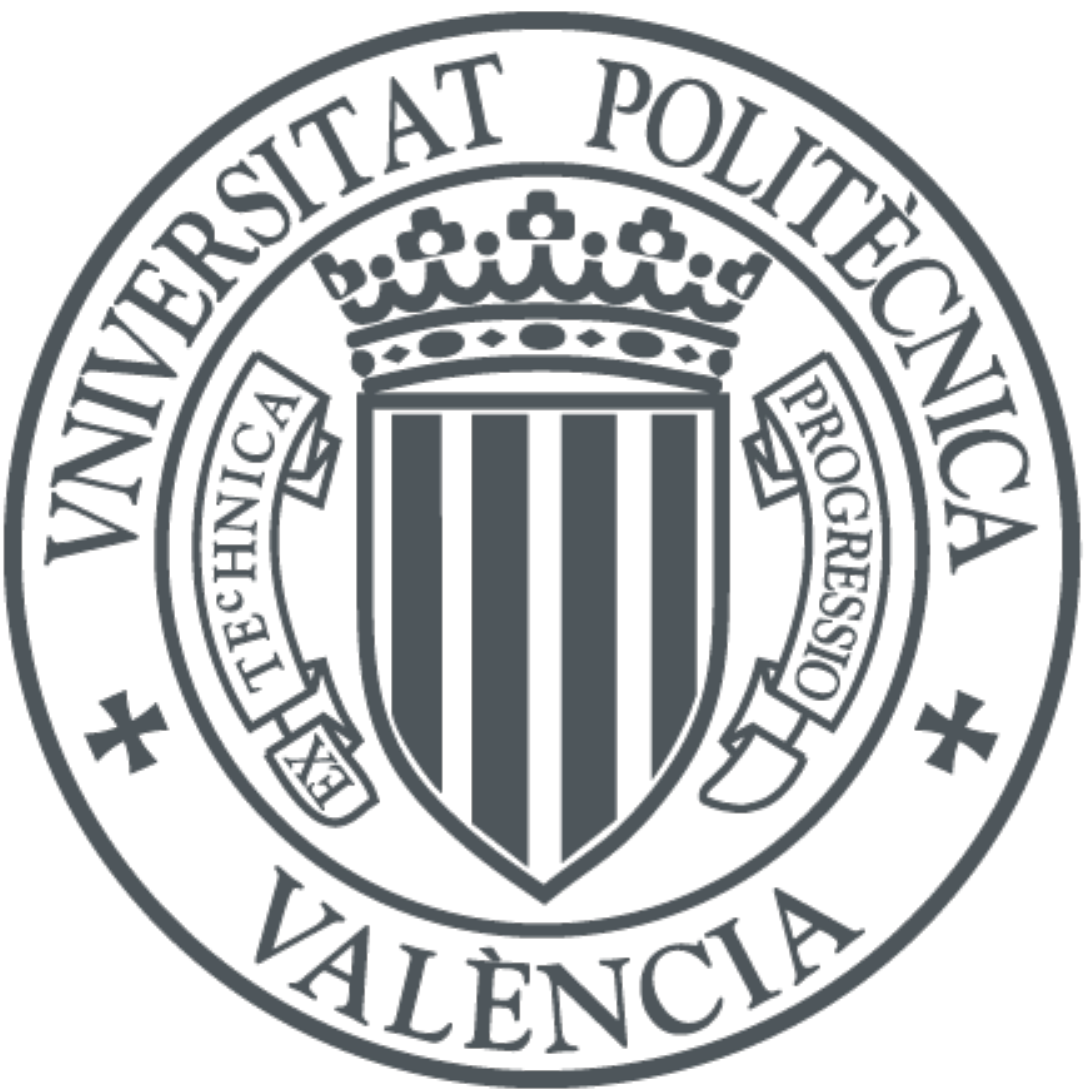

The final publication is available at

http://doi.org/10.1016/j.coastaleng.2016.05.006

Copyright Elsevier

Additional Information 


\title{
Hydraulic stability of nominal and sacrificial toe berms for mound breakwaters on steep sea bottoms
}

\author{
Maria P. Herrera ${ }^{a, *}$, Jorge Molines ${ }^{b}$ and Josep R. Medina ${ }^{c}$ \\ ${ }^{a}$ Research Assistant, Dept. of Transportation, Universitat Politècnica de València, Camino de Vera s/n, 46022

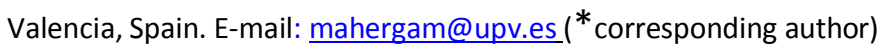 \\ ${ }^{b}$ Research Assistant, Dept. of Transportation, Universitat Politècnica de València, Camino de Vera s/n, 46022 \\ Valencia, Spain. E-mail: jormollo@upv.es \\ ${ }^{b}$ Professor, Dept. of Transportation, Universitat Politècnica de València, Camino de Vera s/n, 46022 Valencia, Spain. \\ E-mail: irmedina@upv.es
}

\section{ABSTRACT}

When mound breakwaters are placed on steep sea bottoms in combination with very shallow waters, the design of the toe berm becomes a relevant issue. Toe berms built close to the water surface on a steep sea bottom must withstand such high wave loads that their design may not be feasible with available quarrystones. In this study, a new design method was developed to reduce the rock size by increasing the toe berm width. The analysis involved specific 2D small-scale tests with toe berms of different rock sizes and widths, placed on a $m=1 / 10$ bottom slope with the water surface close to the toe berm crest. Two new concepts were introduced to better characterize damage to wide toe berms: (1) the most shoreward toe berm area which effectively supports the armor layer, in this study referred to as the primary or "nominal" toe berm and (2) the most seaward toe berm area which serves to protect the nominal toe berm, in this study 
called the secondary or the "sacrificial" toe berm. Damage to the nominal toe berm was used to describe hydraulic stability of wider toe berms. Given a standard toe berm of three rocks wide (nominal toe berm), an equivalent toe berm with damage similar to the nominal toe berm was defined by increasing the berm width and decreasing the rock size. The reduction in rock size showed an inverse 0.4 -power relation with the relative berm width.

Keywords: hydraulic stability; mound breakwater; nominal toe berm; sacrificial toe berm; shallow water; steep sea bottom; toe berm.

Highlights:

a) Toe berm is a relevant design element of mound breakwaters placed on steep sea bottoms combined with very shallow waters.

b) Toe berm damage is critical when the still water level is near the toe berm crest.

c) Toe berms may require rocks larger than the size available at the construction site.

d) Rock size for the toe berm can be reduced by increasing the toe berm width.

\section{Introduction}

The design of rubble mound breakwaters usually focuses on the main armor layer. When concrete armor units are used, it is common to construct a rock toe berm of three to four rocks wide to provide support for the armor layer (see CIRIA/CUR/CEFMEF, 2007). Toe berm stability depends mainly on design wave storm characteristics, water depth and the sea bottom slope existing at the construction site. Toe berms in very shallow 
waters behave in manner a completely different from those built in non-breaking conditions (see Hovestad, 2005). On gentle sea bottoms, it is common to design deep submerged rock toe berms. However, on rocky coastlines with steep sea bottoms, coastal structures may require emerged toe berms with heavy rocks; toe berm hydraulic stability may be even more critical than armor stability. Herrera and Medina (2015) conducted laboratory tests with a steep bottom slope $(m=1 / 10)$ and concluded that most damage occurs when the still water level $(S W L)$ is near the crest of the toe berm. In these conditions, for certain wave storms, the required nominal diameter $\left(D_{n 50}\right)$ may be so large that it is not possible to design standard toe berms with rocks from available quarries. In these cases, Besley and Benechere (2009) and Herrera and Medina (2015) recommended moving the toe position to deeper or shallower waters where it is feasible to construct the toe berm with rock sizes available at the construction site. Nevertheless, if the toe position cannot be moved due to environmental, economic or operational requirements, this design change is not possible. Other design changes for toe berms are given in the literature; authors such as Burcharth and Liu (1995) or Van Gent and Van der Werf (2014) proposed using concrete units for the toe berm, while USACE (2006) suggested excavating trenches, drilling piles or anchoring bolts to the sea bottom to support the toe stones on rocky coastlines.

The most popular formulas to predict damage to rock toe berms were obtained from small-scale tests with different toe berm geometries. However, toe berm widths $\left(B_{t}\right)$ and thicknesses $\left(t_{t}\right)$ were not usually introduced as explicative parameters of the observed toe berm damage. Eq. (1) is equivalent to the formula given by Gerding (1993), which is based on laboratory tests with a bottom slope $m=1 / 20$, two toe berm widths $\left(B_{t}=3 D_{n 50}\right.$ 
and $\left.12 D_{n 50}\right)$, two toe berm thicknesses $\left(t_{t}=2.3 D_{n 50}\right.$ and $\left.8.8 D_{n 50}\right)$, and different water depths at the toe $\left(7.5 D_{n 50} \leq h_{s} \leq 29.4 D_{n 50}\right)$.

$$
N_{\text {od }}=\frac{1}{\left(0.24\left(\frac{h_{t}}{D_{n 50}}\right)+1.6\right)^{1 / 0.15}}\left(N_{s}\right)^{1 / 0.15}
$$

in which $N_{o d}$ is the damage number, $N_{s}=H_{s t} /\left(\Delta D_{n 50}\right)$ is the stability number, $\Delta=$ $\left(\rho_{r}-\rho_{w}\right) / \rho_{w}$ is the relative submerged mass density of rocks, $\rho_{r}$ is the mass density of rocks, $\rho_{\mathrm{w}}$ is the mass density of sea water, $H_{s t}$ is the significant wave height at the toe of the structure, and $h_{t}$ is the water depth above the toe berm.

Eq. (2) is equivalent to the formula proposed by Van der Meer (1998), based on the data given by Gerding (1993), but using the dimensionless parameter $h_{t} / h_{s}$.

$$
N_{o d}=\frac{1}{\left(6.2\left(\frac{h_{t}}{h_{s}}\right)^{2.7}+2.0\right)^{1 / 0.15}}\left(N_{s}\right)^{1 / 0.15}
$$

Ebbens (2009) and Baart et al. (2010) proposed Eq. (3) to estimate the toe berm damage from laboratory tests with three bottom slopes ( $m=1 / 20,1 / 50$ and $1 / 10)$, two toe berm widths $\left(B_{t}=3.7 D_{n 50}\right.$ and $\left.5.3 D_{n 50}\right)$, two toe berm thicknesses $\left(t_{t}=2.2 D_{n 50}\right.$ and $\left.3.2 D_{n 50}\right)$, and different water depths at the toe $\left(2.7 D_{n 50} \leq h_{s} \leq 18 D_{n 50}\right)$.

$N_{\%}=0.038\left(\xi_{0 p}^{*}\right)^{3 / 2}\left(N_{s}\right)^{3}$

in which $N_{\%}$ is the percentage of damage, $\xi_{o p}{ }^{*}=\mathrm{m} /\left(H_{s t} / L_{o p}\right)^{1 / 2}$ is the surf similarity parameter where $m$ is the bottom slope, and $L_{o p}=g T_{p}^{2} / 2 \pi$ is the deep water wave length corresponding to the peak period, $T_{p}$. 
Eq. (4) is equivalent to the formula proposed by Muttray (2013), based on experiments conducted by different authors, including the data given by Gerding (1993) and Ebbens (2009).

$N_{\text {od }}=\left(0.58-0.17 \frac{h_{t}}{H_{s t}}\right)^{3}\left(N_{s}\right)^{3}$

Van Gent and Van der Werf (2014) obtained Eq. (5) from laboratory tests with a bottom slope $m=1 / 30$, two toe berm widths $\left(B_{t}=3 D_{n 50}\right.$ and $\left.9 D_{n 50}\right)$, two toe berm thicknesses $\left(t_{t}\right.$ $=2 D_{n 50}$ and $\left.4 D_{n 50}\right)$, and different water depths $\left(8.6 D_{n 50}<h_{s}<27.4 D_{n 50}\right.$ and $7 D_{n 50} \leq h_{t}$ $\leq 25 D_{n 50}$ ). Eq. (5) explicitly considers the influence of $B_{t}$ and $t_{t}$ on toe berm stability.

$N_{\text {od }}=0.032\left(\frac{t_{t}}{H_{s t}}\right)\left(\frac{B_{t}}{H_{s t}}\right)^{0.3}\left(\frac{\hat{u}_{\delta}}{\sqrt{g H_{s t}}}\right)\left(N_{s}\right)^{3}$

in which $\hat{u}_{\delta}=\frac{\pi H_{s t}}{T_{m-1,0}} \frac{1}{\sinh \left(k h_{t}\right)}, k=\frac{2 \pi}{L_{m-1,0}}=\frac{2 \pi}{\frac{g}{2 \pi} T_{m-1,0}{ }^{2}}, T_{m-1,0}=\frac{m_{-1}}{m_{0}}, m_{i}$ is the $i$-th spectral moment given by $m_{i}=\int_{0}^{\infty} S(f) f^{i} d f$, being $S(f)$ the wave spectrum.

Van Gent and Van der Werf (2014) also proposed multiplying the design $N_{\text {od }}$ value by a factor $f_{B}$ (see Eq. 13) when $3 D_{n 50}<B_{t} \leq 9 D_{n 50}$, as described in Section 6 .

Finally, Eq. (6) proposed by Herrera and Medina (2015) is based on laboratory tests with a steep bottom slope $(m=1 / 10)$, one toe berm width $\left(B_{t}=3 D_{n 50}\right)$, one toe berm thickness $\left(t_{t}=2 D_{n 50}\right)$, and water depths at the toe berm in the range of $-0.5 D_{n 50} \leq h_{s} \leq 5.01 D_{n 50}$. 
$N_{o d}=\left(\frac{\left(H_{s 0} L_{0 p}\right)^{1 / 2}}{\Delta D_{n 50}}-5.5\right)\left[\left(-0.2 \frac{h_{s}}{D_{n 50}}+1.4\right) \exp \left(0.25 \frac{h_{s}}{D_{n 50}}-0.65\right)\right]^{1 / 0.15}$

in which $H_{s 0}$ is the significant deep water wave height. Herrera and Medina (2015) described the two toe berm damage definitions, $N_{o d}$ and $N_{\%}$, used in Eqs. (1) to (6).

$N_{o d}=\frac{N}{B / D_{n 50}}$

in which $N$ is the number of displaced rocks and $B$ is the total width of the wave flume. Herrera and Medina (2015) found that $N_{\%}$ is usually one order of magnitude lower than the damage number $N_{o d}$. Both $N_{o d}$ and $N_{\%}$ take into account the total number of rocks displaced from the toe $(N)$. However, $N$ is not suitable to measure the damage to toe berms with different geometries, since a larger $N$ is required to significantly damage larger toe berms. When increasing the toe berm width $\left(B_{t}>3 D_{n 50}\right)$, rocks situated in the most seaward area do not directly contribute to support the armor, but only to protect the most shoreward area of the toe berm. Since toe berm stability should be considered together with the stability of the main armor layer (see Lamberti, 1994), the most seaward area of the toe structure can be considered as a "sacrificial" toe berm, and the most shoreward area of three nominal diameters wide, as the "nominal" toe berm necessary to support the armor layer (see Fig. 1). 


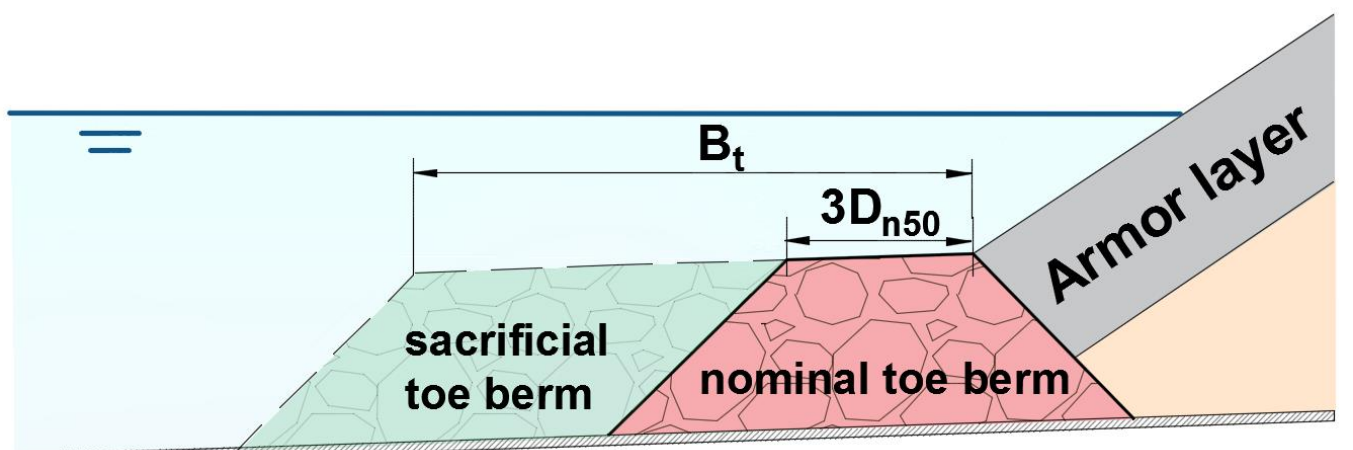

Fig. 1. Sketch of sacrificial and nominal toe berms.

This study analyzes the influence of the nominal diameter $\left(D_{n 50}\right)$ and the toe berm width $\left(B_{t}=n D_{n 50}\right)$ on the hydraulic stability of the nominal toe berm, where $n$ is the number of rock rows placed on the upper layer of the toe berm. To this end, 2D physical tests were conducted using small-scale models of breakwaters with double-layer randomly-placed cube armors and rock toe berms, placed on a steep bottom slope $(m=1 / 10)$. Different pairs of $\left(D_{n 50}, B_{t}\right)$ were tested with the SWL close to the crest of the toe berms. The required rock size given by Eq. (6) for a nominal toe berm $\left(B_{t}=3 D_{n 50}\right)$ was modified to account for wider toe berms $(n>3)$ based on damage measurements of the nominal toe berm. In this paper, the experimental setup is described in Section 2. Tests with different toe berm sizes and widths are analyzed in Section 3. Section 4 describes a design method based on a new equation with its confidence intervals, providing an integrated graph to design rock toe berms. A practical application is given in Section 5. Formulas given in the literature are compared in Section 6. Finally, conclusions are drawn in Section 7.

\section{Physical model tests}

2D physical model tests were conducted in the wind and wave test facility $(30 \mathrm{~m} \times 1.2 \mathrm{~m}$ $x 1.2 \mathrm{~m}$ ) of the Laboratory of Ports and Coasts at the Universitat Politècnica de València 
(LPC-UPV) with a piston-type wavemaker and a steep sea bottom $(m=1 / 10)$. Fig. 2 shows a longitudinal cross section of the LPC-UPV wave flume with the location of the wave gauges used in this study.

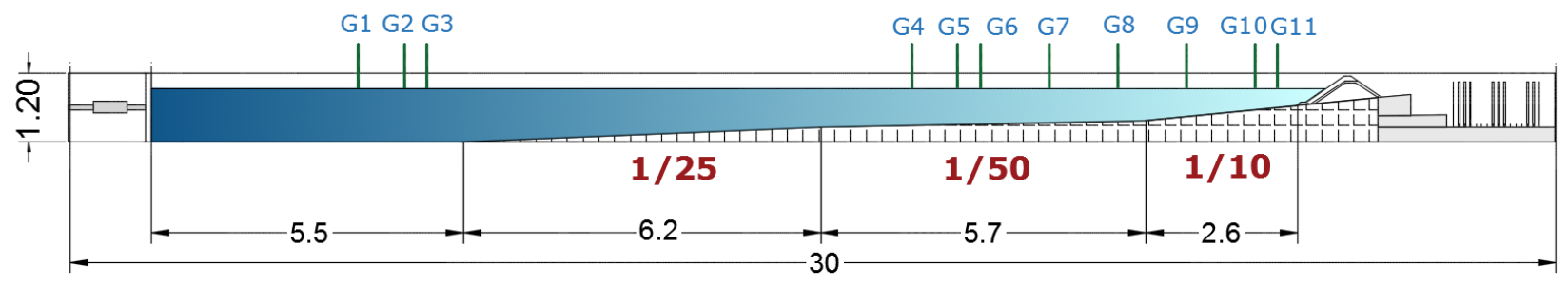

Fig. 2. Longitudinal cross section of the LPC-UPV wave flume (dimensions in meters).

The test model depicted in Fig. 3 corresponds to a conventional $\cot \alpha=\mathrm{H} / \mathrm{V}=3 / 2$ nonovertopped mound breakwater, protected with a double-layer, randomly-placed cube armor with nominal diameter $D_{n}(\mathrm{~cm})=3.97$ and weight $W(\mathrm{~g})=141.5$. The cube armor was built on a filter layer with $D_{n 50}(\mathrm{~cm})=1.78$ and $D_{n 85} / D_{n 15}=1.35$. The granulometric characteristics of the core material were $D_{n 50}(\mathrm{~cm})=0.68$ and $D_{n 85} / D_{n 15}=1.64$.

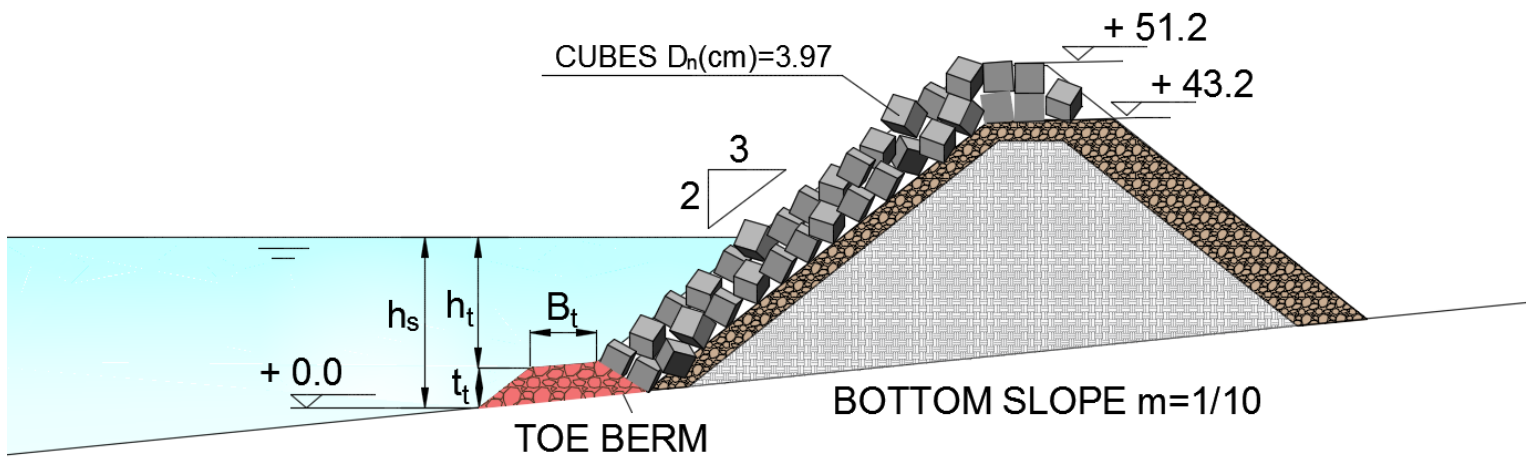

Fig. 3. Configuration of the cube armored model (dimensions in centimeters). 
Toe berms were tested with three rock sizes, $D_{n 50}(\mathrm{~cm})=3.04,3.99$ and 5.12 , with a mass density $\rho_{r}\left(\mathrm{~g} / \mathrm{cm}^{3}\right)=2.70$. Three toe berm widths $(\mathrm{n}=3,5$ and 12$)$ were applied with $D_{n 50}(\mathrm{~cm})=3.04$ and 3.99 ; the nominal toe berm was considered as the most shoreward area of the berm with a width of three times the rock nominal diameter $\left(B_{t}=3 D_{n 50}\right)$. The nominal toe berm was placed first; later, the sacrificial toe berm was placed, using rocks painted in a different color to be easily distinguished. Only the nominal toe berm $(n=3)$ was tested with $D_{n 50}(\mathrm{~cm})=5.12$. In all cases, the toe berm thickness was fixed at $t_{t}=$ $2 D_{n 50}$, and the water depth was $h_{s s}(\mathrm{~cm})=8$, measured at the toe of the nominal toe berm $(n=3)$ for all configurations (see Fig. 4). With $h_{s s}(\mathrm{~cm})=8$, the SWL was very close to the crest of the toe berms $\left(1.5 \leq h_{s s} / D_{n 50} \leq 2.6\right)$. Note that $h_{s}=h_{s s}$ only when $B_{t}=3 D_{n 50}$.
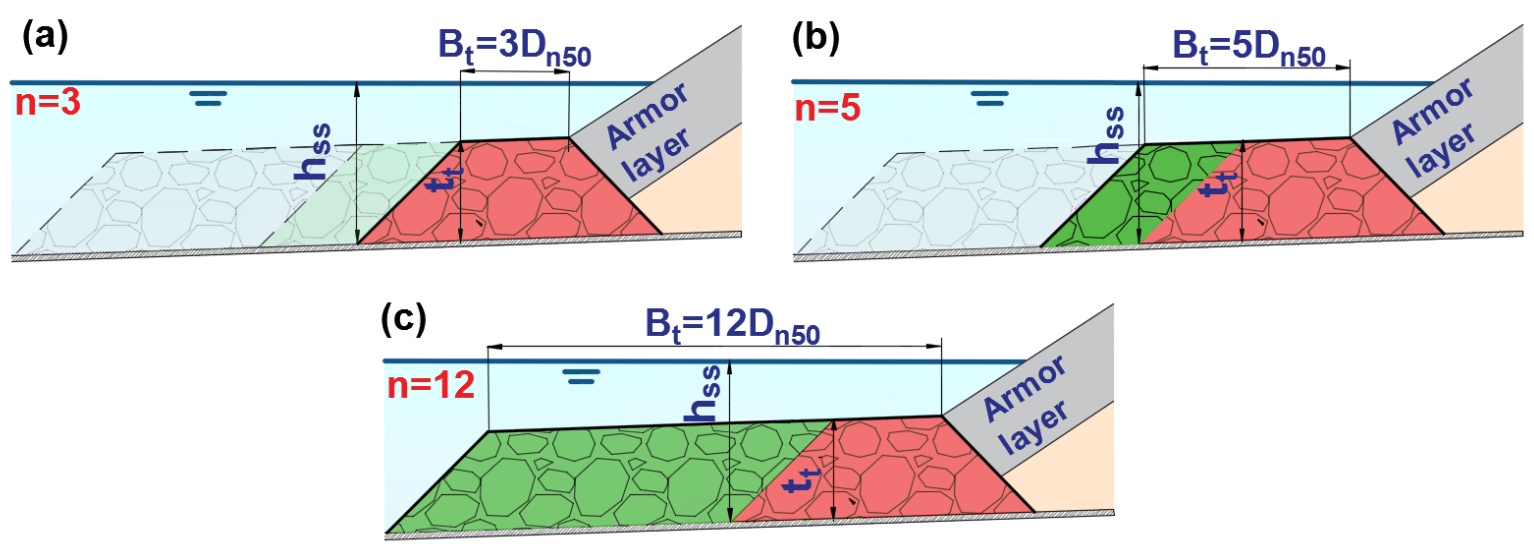

Fig. 4. Configuration of tested toe berms: (a) $B_{t}=3 D_{n 50}$, (b) $B_{t}=5 D_{n 50}$ and (c) $B_{t}=12 D_{n 50}$. Random wave runs of 500 waves were generated following JONSWAP $(\gamma=3.3)$ spectrum, and the AWACS Active Absorption System was activated to avoid multi-reflections. Test series were conducted following the methodology described by Herrera and Medina (2015). Five different peak periods were considered, $T_{p}(s)=1.20,1.50,1.80,2.20$ and 2.40; for each $T_{p}$, values of significant wave height at the wave generating zone $\left(H_{s g}\right)$ 
were increased from no damage to wave breaking in front of the wavemaker. $H_{s g}$ was increased in steps of $2 \mathrm{~cm}$ in the range of $8 \leq H_{s g}(\mathrm{~cm}) \leq 20$. The toe berm was rebuilt after each test series defined by the water depth at the toe of the nominal toe berm $\left(h_{s s}\right)$, the rock size $\left(D_{n 50}\right)$, and the toe berm width $\left(B_{t}=n D_{n 50}\right)$.

Two damage parameters were measured after each test: (1) $N_{o d}$, corresponding to the total damage of the toe berm of width $B_{t}=n D_{n 50}(n \geq 3)$; and (2) $N_{o d} *$ corresponding only to the damage of the nominal toe berm. Fig. 5 shows a model with $D_{n 50}(\mathrm{~cm})=3.99$ and $B_{t}=5 D_{n 50}$; blue rocks correspond to the nominal toe berm and brown rocks correspond to the sacrificial toe berm. Table 1 summarizes the test conditions and the range of parameters used in this study.

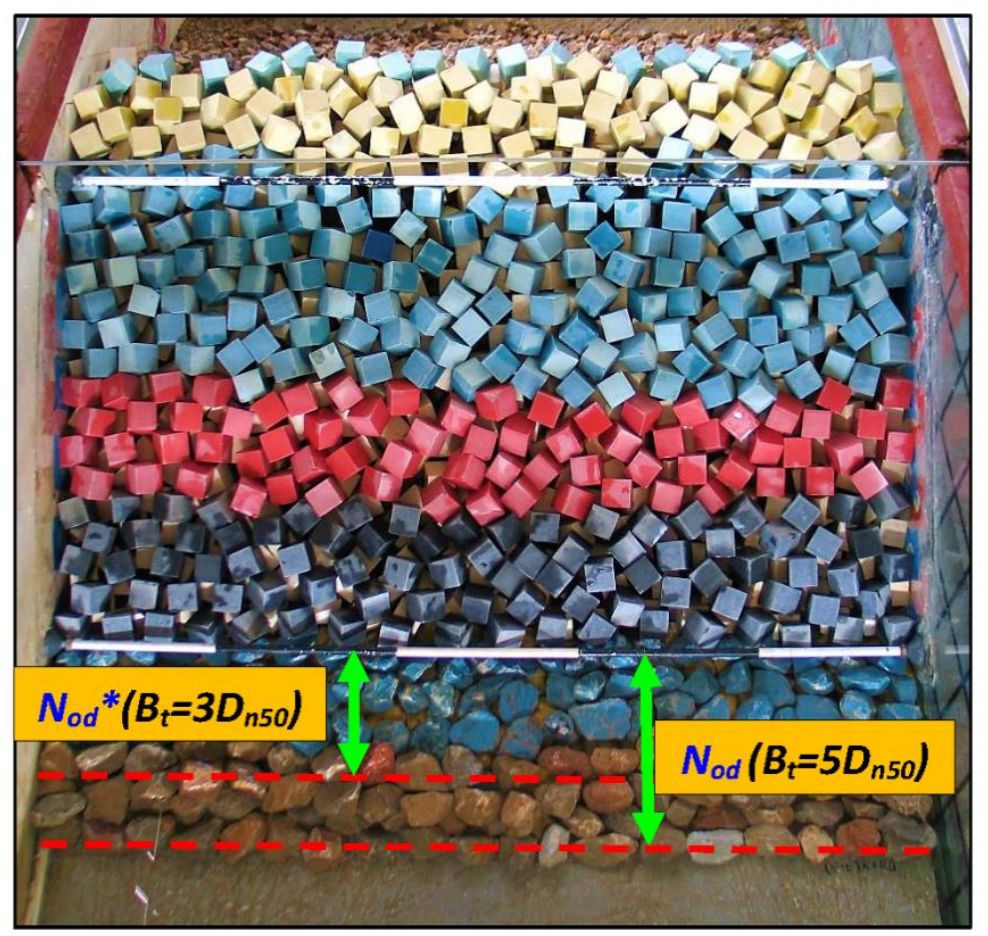

Fig. 5. Nominal (blue rocks) and sacrificial (brown rocks) toe berms with $B_{t}=5 D_{n 50}$.

Table 1. Test conditions. 


\begin{tabular}{|c|c|c|}
\hline Parameter & Symbol & Value \\
\hline Slope angle (-) & $\cot \alpha$ & $3 / 2$ \\
\hline Bottom slope (-) & $m$ & $1 / 10$ \\
\hline Cube armor size $(\mathrm{cm})$ & $D_{n}$ & 3.97 \\
\hline Rock filter size $(\mathrm{cm})$ & $D_{n 50}$ & 1.78 \\
\hline Rock core size $(\mathrm{cm})$ & $D_{n 50}$ & 0.68 \\
\hline Rock toe size $(\mathrm{cm})$ & $D_{n 50}$ & $3.04,3.99$ and 5.12 \\
\hline Rock toe density $\left(\mathrm{g} / \mathrm{cm}^{3}\right)$ & $\rho_{r}$ & 2.7 \\
\hline Relative toe width (-) & $B_{t} / D_{n 50}$ & $3-12$ \\
\hline Relative toe thickness (-) & $t_{t} / D_{n 50}$ & 2 \\
\hline Relative water depth at toe berm (-) & $h_{s} / D_{n 50}$ & $1.5-3.5$ \\
\hline Relative water depth at the nominal toe berm (-) & $h_{s s} / D_{n 50}$ & $1.5-2.6$ \\
\hline Relative significant wave height at generating zone (-) & $H_{s g} / h_{s s}$ & $1.0-2.5$ \\
\hline Wave steepness at generating zone $\left(\mathrm{s}_{\mathrm{gp}}=2 \pi H_{s g} / g T_{p}^{2}\right)(-)$ & $S_{g p}$ & $0.01-0.07$ \\
\hline Stability number at generating zone $\left(N_{s}=H_{s g} / \Delta D_{n 50}\right)(-)$ & $N_{s}$ & $1.0-3.8$ \\
\hline Damage level of the nominal toe berm (-) & $N_{o d}^{*}$ & $<4.8$ \\
\hline Total damage level (-) & $N_{o d}$ & $<11.1$ \\
\hline
\end{tabular}

Water surface elevation was measured using eleven capacitive wave gauges. One group of wave gauges (G1, G2 and G3) was placed near the wavemaker while ten wave gauges (G4 to G11) were placed along the wave flume (see Fig. 2). The LASA-V method described by Figueres and Medina (2004) was used to estimate incident and reflected waves at the generating zone (wave gauges G1, G2 and G3).

\section{Data Analysis}




\subsection{Wave analysis}

Using the water surface elevation, waves were characterized with a time and frequency domain analysis. When dealing with waves breaking on a $m=1 / 10$ bottom slope combined with shallow waters, it is not easy to obtain reliable incident wave characteristics. The deep water wave conditions are the most reliable reference in these cases.

In this study, waves were characterized in deep water conditions following the methodology described in Herrera and Medina (2015). The average of the highest onethird incident waves $\left(H_{i, 1 / 3}\right)$ measured at $\mathrm{G} 1, \mathrm{G} 2$ and $\mathrm{G} 3$ was used to estimate the deep water significant wave height $\left(H_{s 0}\right)$ using the shoaling coefficients given by Goda (2000). Fig. 6 shows the measured $H_{1 / 3, i}$ versus the deep water significant wave height $\left(H_{s 0}\right)$ estimated using the methodology given in Goda (2000).

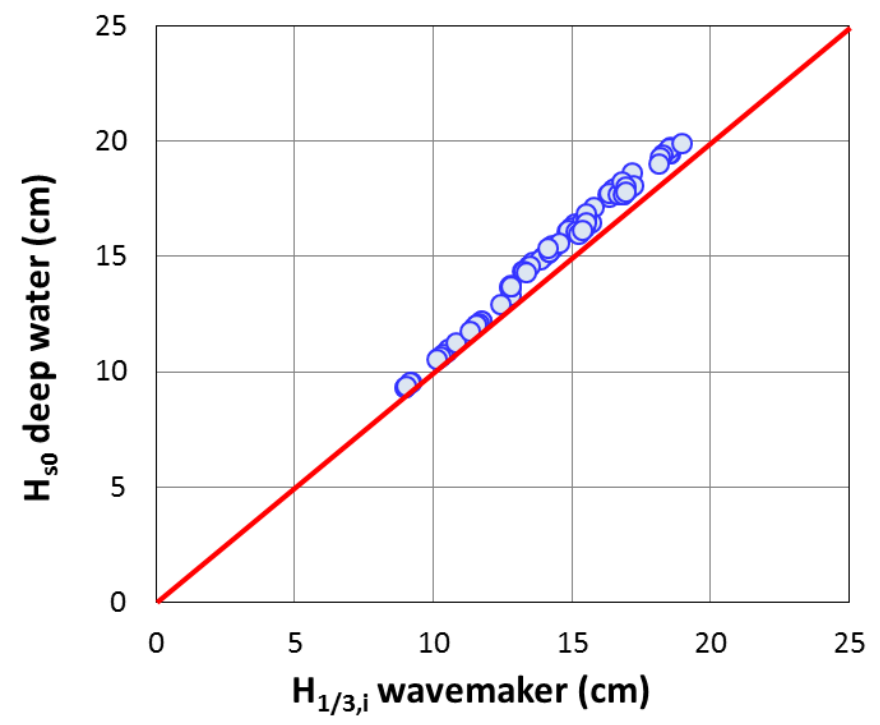

Fig. 6. Measured $H_{1 / 3, i}$ at the wave generating zone versus deep water significant wave height, $H_{s o}$. 
The deep water significant wave height $\left(H_{s 0}\right)$ and the deep water wave length obtained from the peak period $\left(L_{o p}=g T_{p}^{2} / 2 \pi\right)$ were used to characterize the toe berm damage. According to Herrera and Medina (2015), $\left(H_{s o} L_{o p}\right)^{1 / 2}$ seems to be the best explicative variable to represent toe berm damage in very shallow waters combined with steep sea bottoms.

\subsection{Damage analysis}

Toe berm stability was analyzed using the total toe berm damage $\left(N_{o d}\right)$, along with the nominal toe berm damage $\left(N_{o d}{ }^{*}\right)$. After each test, the total number of rocks displaced from the toe berm $(N)$ were counted and the damage parameter, $N_{o d}$, was determined using Eq. (7). Nod corresponded to the damage to both the sacrificial and nominal toe berms. The damage parameter, $N_{o d}{ }^{*}$, was also determined using Eq. (7) but considering only the number of rocks displaced from the nominal toe berm (Fig. 7). Both damage parameters considered the cumulative damage of each test series.

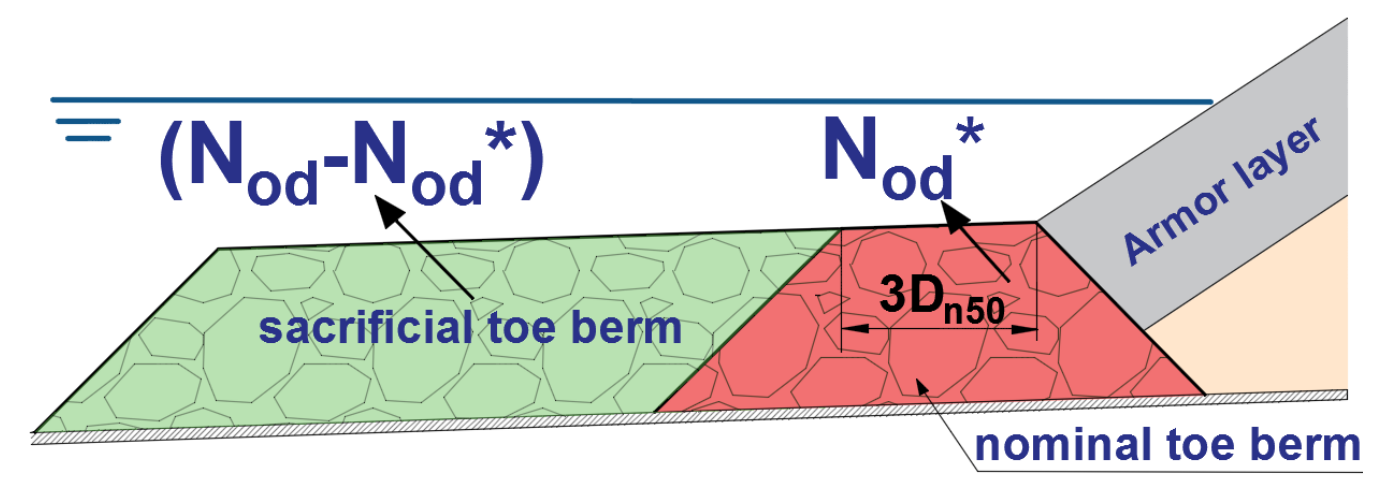

Fig. 7. Total toe berm damage $\left(\mathrm{N}_{\mathrm{od}}\right)$ and nominal toe berm damage $\left(\mathrm{N}_{\mathrm{od}}{ }^{*}\right)$.

Figs. 8 and 9 show total and nominal toe berm damage corresponding to $D_{n 50}(\mathrm{~cm})=$ 3.04, 3.99 and 5.12 and different toe berm widths ( $n=3,5$ and 12$)$. Only the maximum cumulative damage obtained after test runs characterized by $T_{p}$ is plotted here. 


\subsubsection{Total toe berm damage ( $\mathrm{N}_{\mathrm{od}}$ )}

Fig. 8 shows the measured $N_{o d}$ as a function of the variable $\left(H_{s o} L_{o p}\right)^{1 / 2}$ for the seven tested models. $N_{o d}$ increased almost linearly with the variable $\left(H_{s o} L_{o p}\right)^{1 / 2}$ in all cases. Given $n, N_{o d}$ was larger when reducing $D_{n 50}$. Given $D_{n 50}, N_{o d}$ increased when increasing n. Smaller rock sizes and wider toe berms led to larger values of total toe berm damage $\left(N_{o d}\right)$

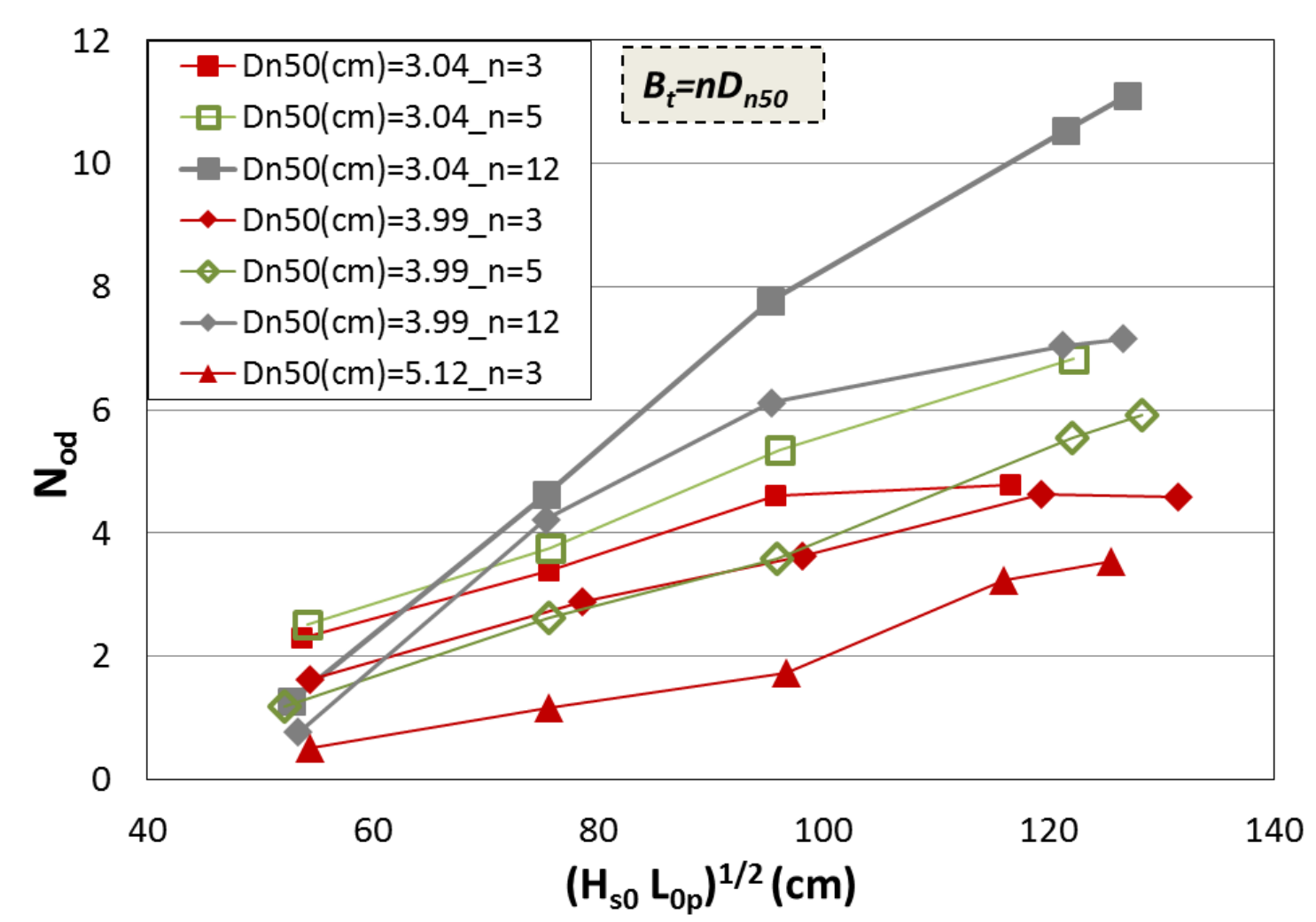

Fig. 8. Total toe berm damage $\left(N_{o d}\right)$ as a function of toe berm width $\left(B_{\mathrm{t}}=n D_{n 50}\right)$ and rock size $\left(D_{n 50}\right)$.

\subsubsection{Nominal toe berm damage $\left(\mathrm{N}_{\mathrm{od}}{ }^{*}\right)$}

Fig. 9 shows the measured nominal toe berm damage $\left(N_{o d}^{*}\right)$ as a function of the variable $\left(H_{s 0} L_{o p}\right)^{1 / 2}$. Given a toe berm width $\left(B_{t}=n D_{n 50}\right), N_{o d} *$ was larger when reducing $D_{n 50}$. 
Given a rock size $\left(D_{n 50}\right), N_{o d}$ increased when reducing the toe berm width $(n)$. Thus, larger rock sizes as well as wider toe berms led to less nominal toe berm damage $\left(N_{o d}{ }^{*}\right)$.

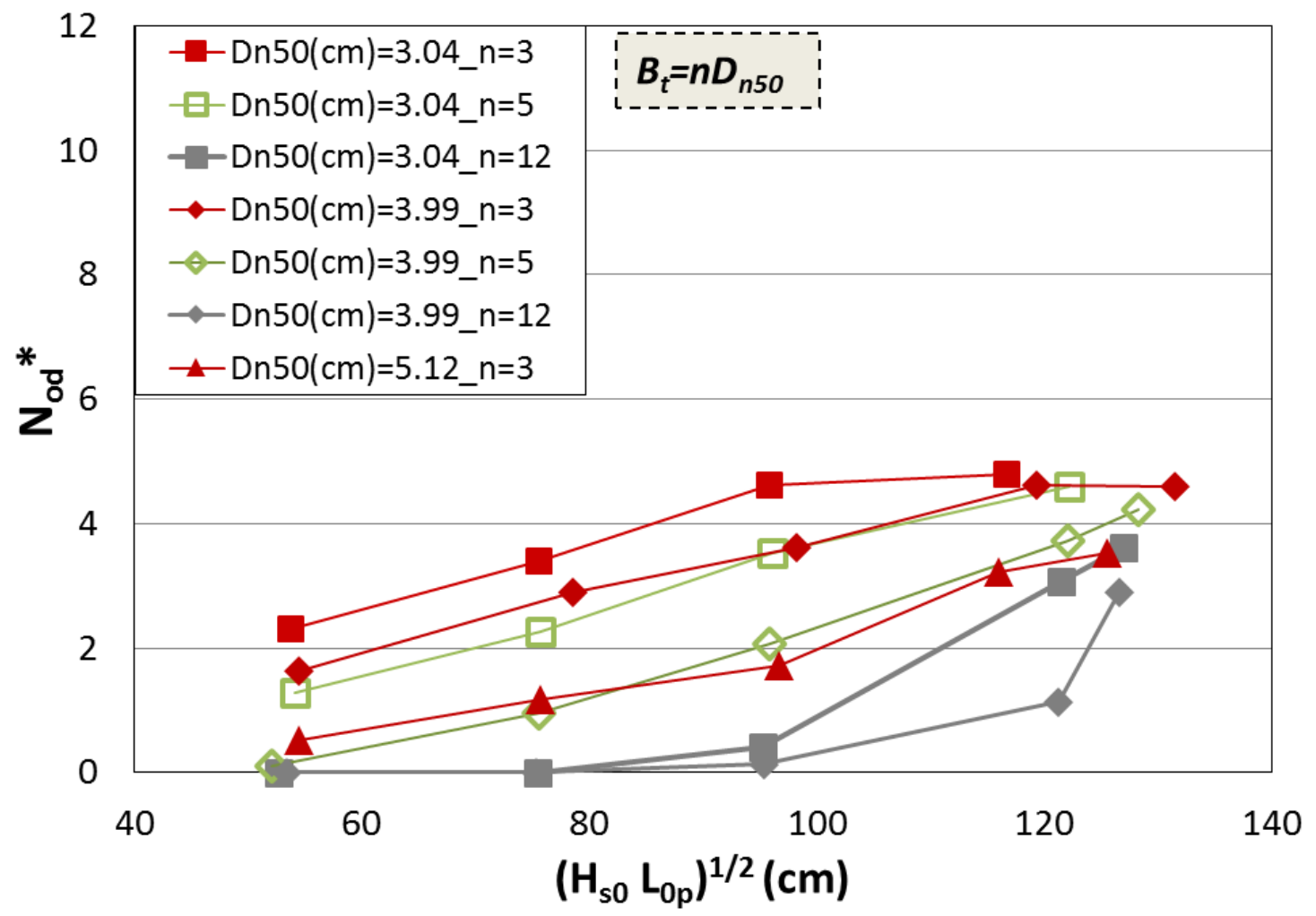

Fig. 9. Nominal toe berm damage $\left(N_{o d^{*}}\right)$ as a function of toe berm width $\left(B_{\mathrm{t}}=n D_{n 50}\right)$ and rock size $\left(D_{n 50}\right)$.

\subsubsection{Comparison of total and nominal toe berm damage measurements}

Fig. 10 compares measured total toe berm damage $\left(N_{o d}\right)$ and nominal toe berm damage $\left(N_{o d}{ }^{*}\right)$. The wider the toe berm, the lower the $N_{o d}{ }^{*}$ but the higher the $N_{o d}$. Given a rock size $\left(D_{n 50}\right)$, a wider toe berm would reduce $N_{o d}{ }^{*}$, although the $N_{o d}$ would increase. Thus, the total toe berm damage $\left(N_{o d}\right)$ is not a good estimator of the hydraulic stability of toe berms when comparing different berm widths $\left(B_{t}>3 D_{n 50}\right)$; the $N_{o d}{ }^{*}$ corresponding to the damage to the nominal toe berm, which is actually supporting the armor layer, is the toe berm damage which should be taken into account when analyzing breakwater 
hydraulic stability. Damage observed on the sacrificial toe berm is not relevant when analyzing the hydraulic performance of mound breakwaters.

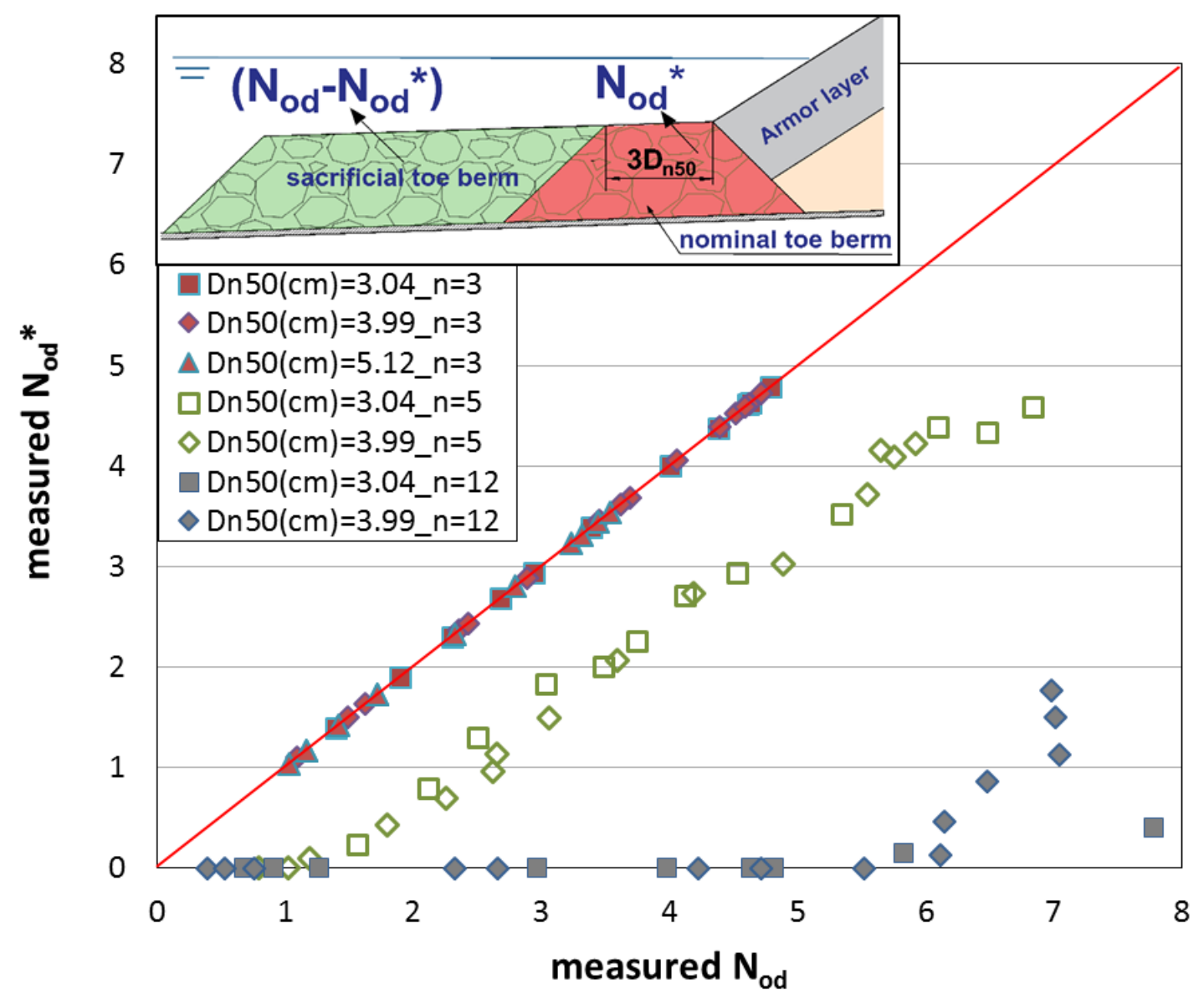

Fig. 10. Comparison of measured total toe berm damage $\left(N_{o d}\right)$ and measured nominal toe berm damage $\left(N_{o d}^{*}\right)$.

Hereafter, only the damage to the nominal toe berm, $N_{o d}{ }^{*}$, is considered. Eq. (6), proposed by Herrera and Medina (2015), is extended here to design toe berms with $3 D_{n 50} \leq B_{t} \leq 12 D_{n 50}$ and $t_{t}=2 D_{n 50}$, placed on steep sea bottoms $(m=1 / 10)$ when the SWL is close to the crest of the toe berm $\left(1.5 \leq h_{s s} / D_{n 50} \leq 2.6\right), 0.02 \leq \mathrm{s}_{0 p} \leq 0.07$ and $0.4 \leq h_{s s} / H_{s 0}$ $\leq 1.0$.

\section{New design method for toe berms in shallow water and $m=1 / 10$}


Fig. 9 shows that several tests with different $D_{n 50}$ and $n$ provided similar values of $N_{o d}$ * for specific wave conditions, $\left(H_{s o} L_{o p}\right)^{1 / 2}$. Under the same wave conditions $\left(H_{s o}, T_{p}\right)$, the toe berm with $D_{n 50}(\mathrm{~cm})=3.99$ and $n=5$ provided almost the same $N_{o d}{ }^{*}$ as the toe berm with $D_{n 50}(\mathrm{~cm})=5.12$ and $n=3$. Analogously, the toe berm with $D_{n 50}(\mathrm{~cm})=3.04$ and $n=5$ gave values of $N_{o d}{ }^{*}$ similar to those of the toe berm with $D_{n 50}(\mathrm{~cm})=3.99$ and $n=3$. These findings suggest that the rock size can be reduced by increasing the toe berm width. It is possible to keep $N_{o d}$ * constant by reducing $D_{n 50}$ and increasing $n$, or vice versa. The relationship between $D_{n 50}$ and $N_{o d}{ }^{*}$ can be described by Eq. (8), using as a reference the nominal toe berm $(n=3)$ with rock size $D_{n 50}=D_{n 50,3}$.

$$
\frac{D_{n 50, n}}{D_{n 50,3}}=\left(\frac{3}{n}\right)^{k}
$$

where $D_{n 50,3}$ is the nominal diameter of rocks for the nominal toe berm $(n=3), D_{n 50, n}$ is the nominal diameter of rocks for wider toe berms $(3<n \leq 12)$, and $k$ is a positive parameter to be calibrated using the test results described above $(k=0.4)$. Eq. (8) indicates that given a nominal toe berm with $n=3$ and $D_{n 50}=D_{n 50,3}$, an equivalent toe berm can be defined with higher $n(n>3)$ and lower $D_{n 50}\left(D_{n 50, n}<D_{n 50,3}\right)$ to provide $\operatorname{similar} N_{o d}^{*}$.

Because Eq. (6) is valid to design toe berms using rocks with $n=3$, the estimated $N_{o d}$ given by Eq. (6) corresponds to the nominal toe berm damage $\left(N_{o d}{ }^{*}\right)$, and Eqs. (6) and (8) can be combined as follows: 


$$
\begin{aligned}
& N_{o d}{ }^{*}=\left(\frac{\left(H_{s 0} L_{0 p}\right)^{1 / 2}}{\Delta D_{n 50, n}\left(\frac{n}{3}\right)^{k}}-5.5\right) \\
& x\left[\left(-0.2 \frac{h_{s s}}{D_{n 50, n}\left(\frac{n}{3}\right)^{k}}+1.4\right) \exp \left(0.25 \frac{h_{s s}}{D_{n 50, n}\left(\frac{n}{3}\right)^{k}}-0.65\right)\right]^{1 / 0.15}
\end{aligned}
$$

The best agreement between the measured $N_{o d}{ }^{*}$ and the estimated $N_{o d}{ }^{*}$ given by Eq.

(9) was found for $k=0.4$. The goodness of fit between measured and calculated values and the $90 \%$ confidence interval are described below.

Eq. (9) extends the application range of Eq. (6) to deal with wider toe berms. Eq. (9) with $k=0.4$ provides the required rock size for toe berms with $3 D_{n 50} \leq B_{t} \leq 12 D_{n 50}$ and $t_{t}=2 D_{n 50}$, placed on a $m=1 / 10$ sea bottom with $1.5 \leq h_{s s} / D_{n 50} \leq 2.6,0.02 \leq \mathrm{s}_{0 \mathrm{p}} \leq 0.07,0.4 \leq h_{s s} / H_{s 0}$ $\leq 1.0$, using the damage parameter $N_{o d}{ }^{*}$. When designing with $N_{o d}{ }^{*}$, common values for acceptable damage may be directly used. In this study, the criterion proposed by Herrera and Medina (2015) was considered: no significant movement of toe berm rocks $\left(N_{o d}{ }^{*}<\right.$ $0.5)$, significant rock movements $\left(N_{o d}{ }^{*}=1.0\right)$, moderate damage but toe berm still providing support to the armor $\left(N_{o d} *=2.0\right)$, and toe berm failure $\left(N_{o d} *=4.0\right)$.

\subsection{Confidence intervals}

Assuming a Gaussian error distribution, the $90 \%$ confidence interval for the toe berm damage estimation given by Eq. (9) is:

$N_{\text {od }} *{ }_{5 \%}^{95 \%}=N_{\text {od }} * \pm 0.83$ 
Fig. 11 compares measured $N_{o d}{ }^{*}$ and that estimated given by Eq. (9) with the $90 \%$ confidence interval given by Eq. (10). The few outliers for small $N_{o d}{ }^{*}$ shown in Fig. 11 are on the safe side, estimated $N_{o d}{ }^{*}>$ measured $N_{o d}{ }^{*}$.

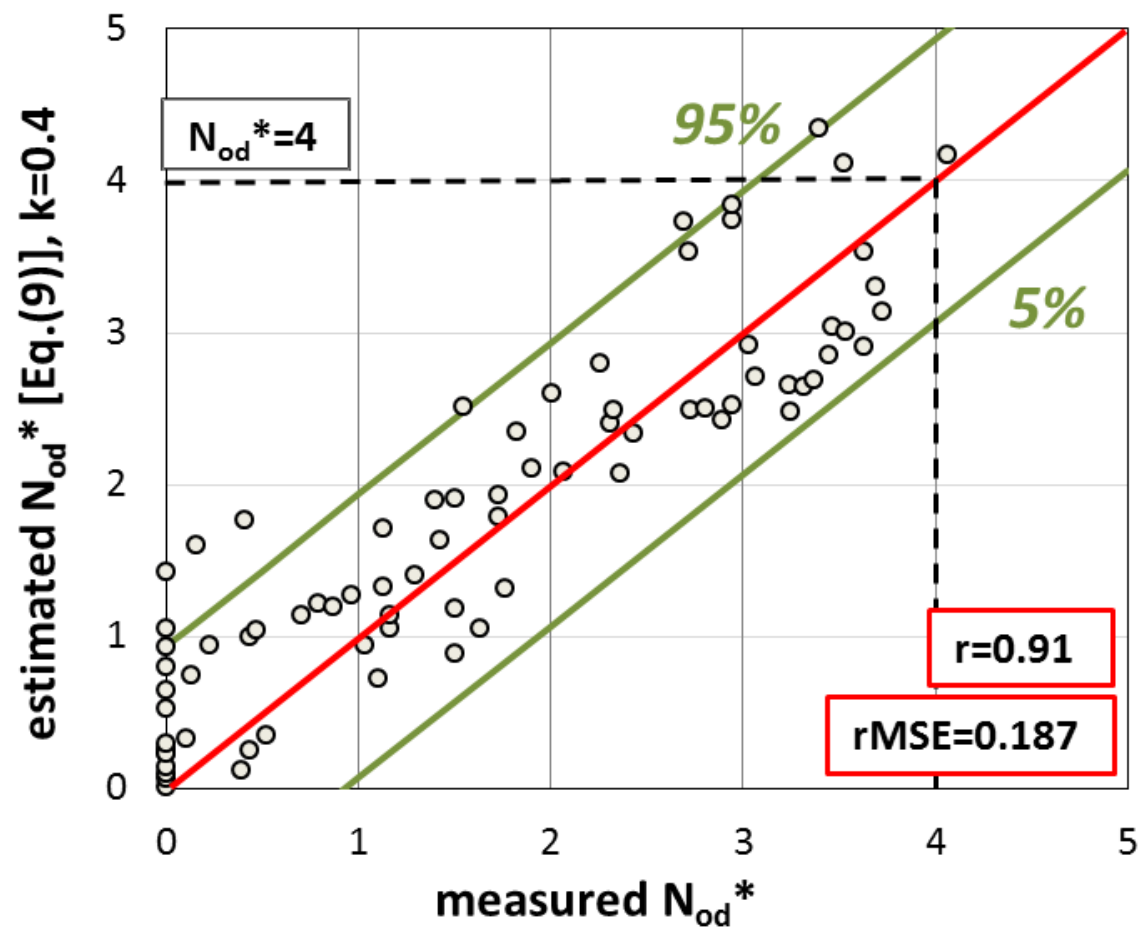

Fig. $11.90 \%$ confidence interval of estimated $N_{o d} *$ given by Eq. (9) with $k=0.4$.

In order to measure the goodness of fit between the $N_{o d}{ }^{*}$ measured in the tests and that estimated by Eq. (9), the relative mean squared error (rMSE) and the correlation coefficient $(r)$ were calculated:

$$
\begin{gathered}
r M S E=\frac{M S E}{V A R}=\frac{\frac{1}{N_{t}} \sum_{i=1}^{N_{t}}\left(t_{i}-e_{i}\right)^{2}}{\frac{1}{N_{t}} \sum_{i=1}^{N_{t}}\left(t_{i}-\bar{t}\right)^{2}} \\
r=\frac{\sum_{i=1}^{N_{t}}\left(t_{i}-\bar{t}\right)\left(e_{i}-\bar{e}\right)}{\sqrt{\sum_{i=1}^{N_{t}}\left(t_{i}-\bar{t}\right)^{2} \sum_{i=1}^{N_{t}}\left(e_{i}-\bar{e}\right)^{2}}}
\end{gathered}
$$


in which MSE is the mean squared error, $N_{t}$ is the number of observations, $t_{i}$ is the target value, $e_{i}$ is the estimated value, VAR is the variance of target values, and $\bar{t}$ and $\bar{e}$ are the average of target and estimated values, respectively. $0 \leq r M S E \leq 1$ estimates the proportion of variance in the observed values not explained by Eq. (9); the lower the $r M S E$, the better the predictions. $0 \leq r \leq 1$ measures the degree of correlation between measured and estimated values of $N_{o d}$; the higher the $r$, the better the predictions. Eq. (9) with $k=0.4$ provided $r M S E=0.187$ and $r=0.91$.

\subsection{Design approach for equivalent toe berms}

Given an acceptable level of damage (e.g. $N_{o d}{ }^{*}=0.5$ or 1.0 ), Eq. (6) is used first to calculate the rock size for a nominal toe berm, $D_{n 50,3}$, and Eq. (9) can be used later to define wider toe berms $(3<n \leq 12)$ with smaller rocks $\left(D_{n 50, n}\right)$.

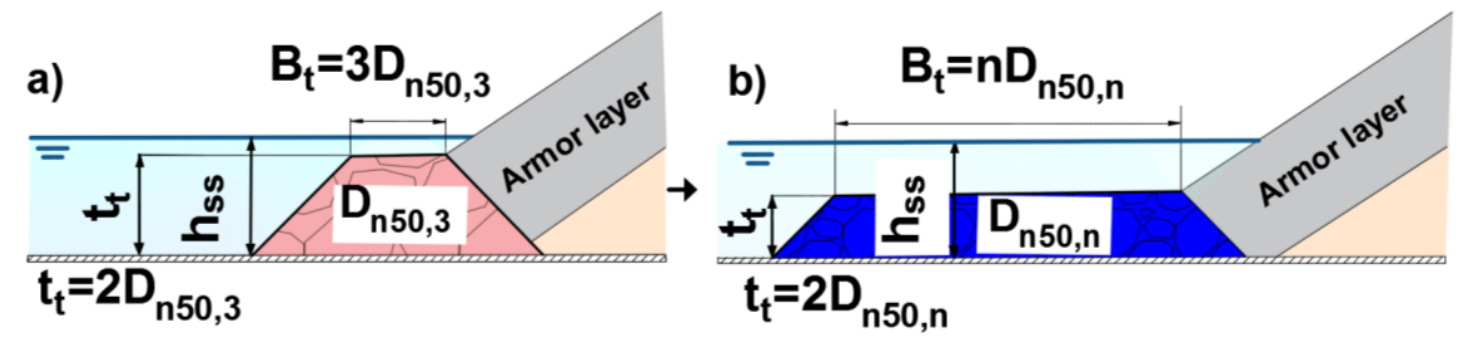

Fig. 12. (a) Nominal toe berm $(n=3)$ and (b) equivalent wider toe berm $(3<n \leq 12)$.

A practical application of this process is given by the design graph shown in Fig. 13, which is valid for $N_{o d}{ }^{*}=0.5$ and 1.0. Fig. 13a shows the nominal diameter of rocks for a nominal toe berm $\left(D_{n 50,3}\right)$, estimated with Eq. (6), as a function of the deep water wave conditions, $\left(H_{s o} L_{O p}\right)^{1 / 2}$, for $h_{s s} / D_{n 50,3}=1.5,2.0$ and 2.5. Fig. $13 \mathrm{~b}$ shows the relation between nominal diameters $\left(D_{n 50,3}\right.$ and $\left.D_{n 50, n}\right)$ as a function of the toe berm width ( $3 \leq n$ $\leq 12)$. $D_{n 50, n}$ can be selected by the designer considering the rock sizes available at the 
construction site. The ranges of application of Eq. (6) in Fig. 13 are $0.02<s_{0 p}<0.07,-0.15<$

$h_{s s} / H_{s 0}<1.5$, and $-0.5 \leq h_{s s} / D_{n 50,3} \leq 5.01$.

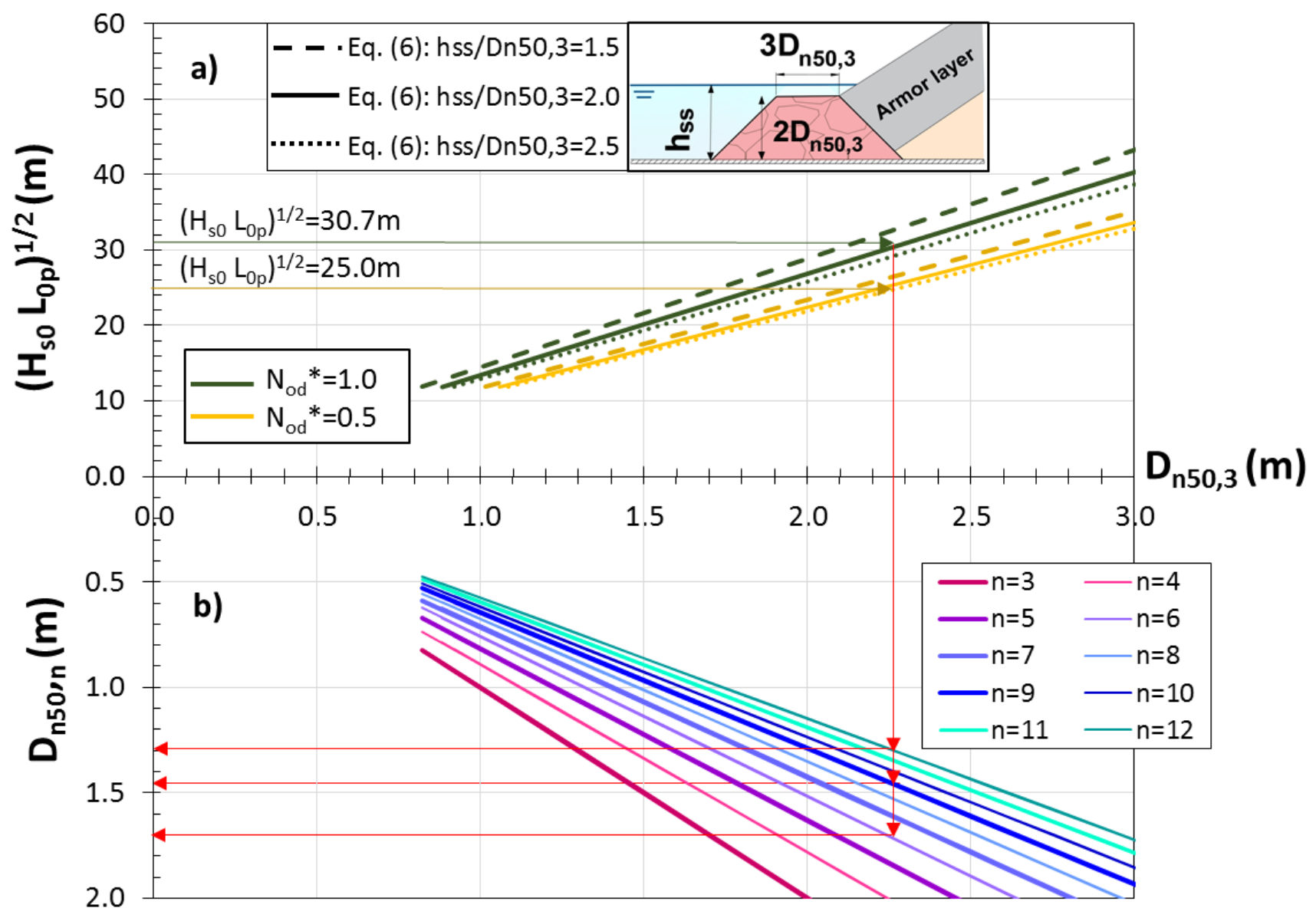

Fig. 13. (a) $D_{n 50,3}$ estimated with Eq. (6) and (b) $D_{n 50, n}$ as a function of $D_{n 50,3}$ and the toe berm width $(n)$.

Red arrows in Fig. 13 indicate the relationship considered in the example given below.

\section{Application example}

In this section, an example is given to design a rock toe berm placed on a $m=1 / 10$ sea bottom combined with a SWL close to the crest of the toe berm $\left(h_{s s} \approx 2 D_{n 50}\right)$; the recommended design value of $N_{o d}{ }^{*}=1$, given by Herrera and Medina (2015) for Eq. (6), 
is considered first. According to Eq. (6) and given a typical design storm for the Alboran Sea $\left(H_{s o}(\mathrm{~m})=5, T_{p}(\mathrm{~s})=11,\left(H_{s 0} L_{o p}\right)^{1 / 2}=30.7 \mathrm{~m}\right.$ and water depth at the nominal toe berm $\left.h_{s s}(\mathrm{~m})=4.5\right)$, the required rock size for a nominal toe berm $\left(B_{t}=3 D_{n 50}\right.$ and $\left.t_{t}=2 D_{n 50}\right)$ is $D_{n 50,3}(\mathrm{~m})=2.23$, which corresponds to 30-tonne rocks if the mass density is $\rho_{r}\left(\mathrm{~g} / \mathrm{cm}^{3}\right)=$ 2.70. In order to reduce the size of the required rocks (if not available at quarry), Eq. (9) with $k=0.4$ is applied. When considering a double toe berm width $(n=6)$, the required rock size is reduced to $D_{n 50, n}(\mathrm{~m})=1.7$ (13-tonne rocks). If only 6-tonne rocks are available at the construction site, a wider toe berm with $n=12$ is required. Fig. 14 depicts the rock weight $(W)$ in tonnes depending on the toe berm width $(n)$. Rocks with $W(\mathrm{t})=30,13,8.0$ and $5.7\left(D_{n 50}(\mathrm{~m})=2.23,1.7,1.44\right.$ and 1.28$)$ could be used when considering toe berm widths having $n=3,6,9$ and 12 , respectively.

If $N_{o d}{ }^{*}=0.5$ rather than $N_{o d}{ }^{*}=1.0$ were considered as the design condition, the toe berms described above would withstand a design storm, $\left(H_{s o} L_{O p}\right)^{1 / 2}=25.0 \mathrm{~m}$, which corresponds to a weaker design storm: $H_{s o}(\mathrm{~m})=4$ and $\left.T_{p}(\mathrm{~s})=10\right)$.

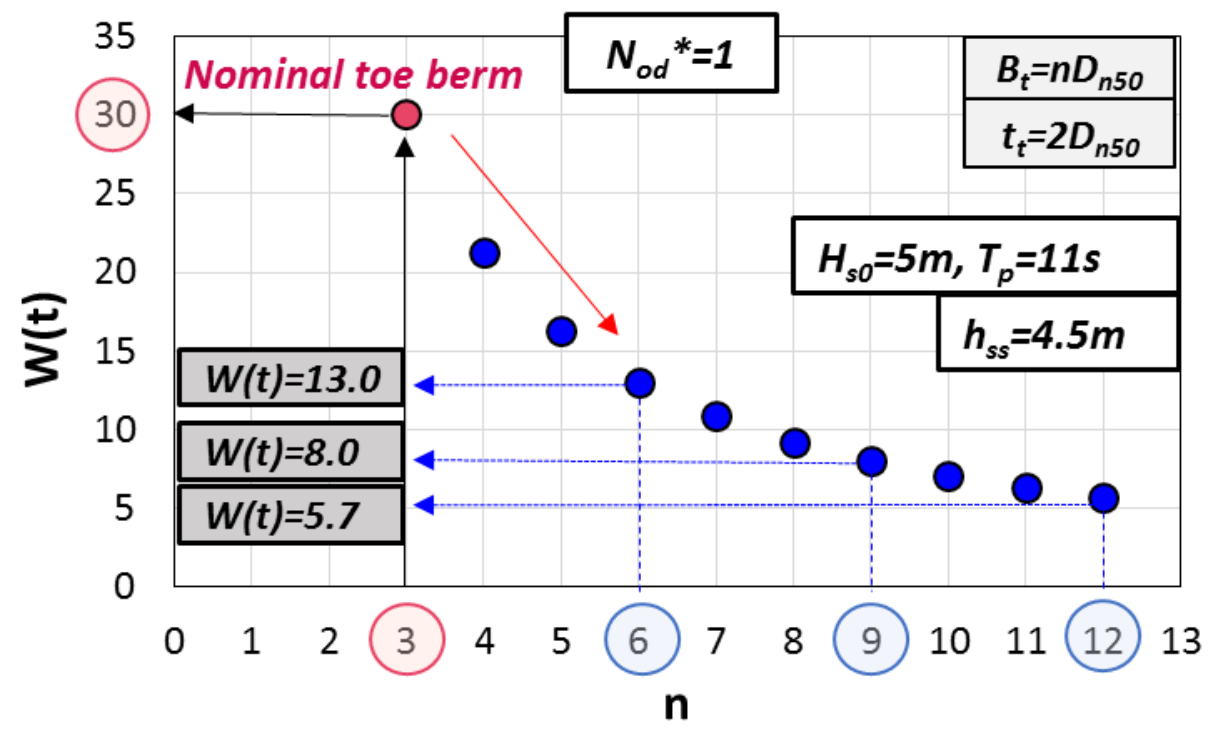

Fig. 14. Rock weight $(W)$ depending on the toe berm width $\left(B_{t}=n D_{n 50}\right)$. 


\section{Comparison with existing formulas}

As mentioned in Section 1, Van Gent and Van der Werf (2014) specifically introduced the toe berm width $\left(B_{t}\right)$ as an explicative parameter of toe berm damage $\left(N_{o d}\right)$. For a certain amount of acceptable damage, the required rock size according to the study by these experts is given by Eq. (5), which was obtained from laboratory tests with a $m=$ 1/30 bottom slope, and no severe depth-limited wave breaking. Two toe berm widths were considered $\left(B_{t}=3 D_{n 50}\right.$ and $\left.9 D_{n 50}\right)$, and only the total toe berm damage $\left(N_{o d}\right)$ was measured after each test. In order to consider that $N_{o d}$ increases with the toe berm width, these authors proposed multiplying the design $N_{o d}$ value by a factor $f_{B}$ when $3 D_{n 50}<B_{t} \leq 9 D_{n 50}$.

$f_{B}=\left(\frac{B_{t}}{3 D_{n 50}}\right)^{1 / 2}=\left(\frac{n}{3}\right)^{1 / 2}$

Thus, when $B_{t}=3 D_{n 50}$, Eq. (5) is directly applicable with $N_{s}=H_{s t} /\left(\Delta D_{n 50}\right)$ and $D_{n 50}=D_{n 50,3}$. If $3 D_{n 50}<B_{t}=n D_{n 50} \leq 9 D_{n 50}$ and $t_{t}=2 D_{n 50}$, Eq. (5) may be rewritten as follows:

$D_{n 50, n}=0.32\left(\frac{H_{s t}}{\Delta\left(N_{o d} f_{B}\right)^{1 / 3}}\right)\left(\frac{2 D_{n 50, n}}{H_{s t}}\right)^{1 / 3}\left(\frac{n D_{n 50, n}}{H_{s t}}\right)^{0.1}\left(\frac{\hat{u}_{\delta}}{\sqrt{g H_{s t}}}\right)^{1 / 3}$

Eq. (14) is equivalent to Eq. (5) for $n=3$. Manipulating Eqs. (5) and (14) and replacing $f_{B}$ by the expression given by Eq. (13), the relation between the required nominal diameters for the design of a toe berm with $3<n \leq 9$ and a nominal toe berm with $n=3$, can be calculated using Eq. (15).

$\frac{D_{n 50, n}}{D_{n 50,3}}=\left(\frac{3}{n}\right)^{1 / 6} \cdot\left(\frac{D_{n 50, n}}{D_{n 50,3}}\right)^{1 / 3} \cdot\left(\frac{n D_{n 50, n}}{3 D_{n 50,3}}\right)^{0.1}=\left(\frac{3}{n}\right)^{\frac{2}{17}}$ 
$D_{n 50, n} / D_{n 50,3}$ follows the potential relationship given by Eq. (8) but with the shape parameter $k=2 / 17$ instead of $k=0.4$ used in Eq. (9). Fig. 15 shows the $N_{o d}{ }^{*}$ measured in this study and that estimated by Eq. (9) when using $k=2 / 17$ rather than $k=0.4$. Eqs. (5) and (14) given by Van Gent and Van der Werf (2014) are valid for toe structures placed on a $\mathrm{m}=1 / 30$ bottom slope, with an armor slope $\cot \alpha=2.0,3 D_{n 50} \leq B_{t} \leq 9 D_{n 50}, 2 D_{n 50} \leq t_{t}$ $\leq 4 D_{n 50}, 7 D_{n 50}<h_{t} \leq 25 D_{n 50}, 1.2 \leq h_{s} / H_{s t} \leq 4.5$ and $0.012 \leq s_{0 p} \leq 0.042$. Eqs. (5) and (14) are beyond the range of variables tested in this study; this explains the poor agreement between the $N_{o d}{ }^{*}$ measured in this study and that estimated by Eq. (9) when using $k=$ $2 / 17$ (instead of $k=0.4$ ). Further research is required to test the range of variables not included in Van Gent and Van der Werf (2014) or in the present study (e.g. $3.5 D_{n 50}<h_{s}<8.6 D_{n 50}$ and $\left.1 / 30<m<1 / 10\right)$.

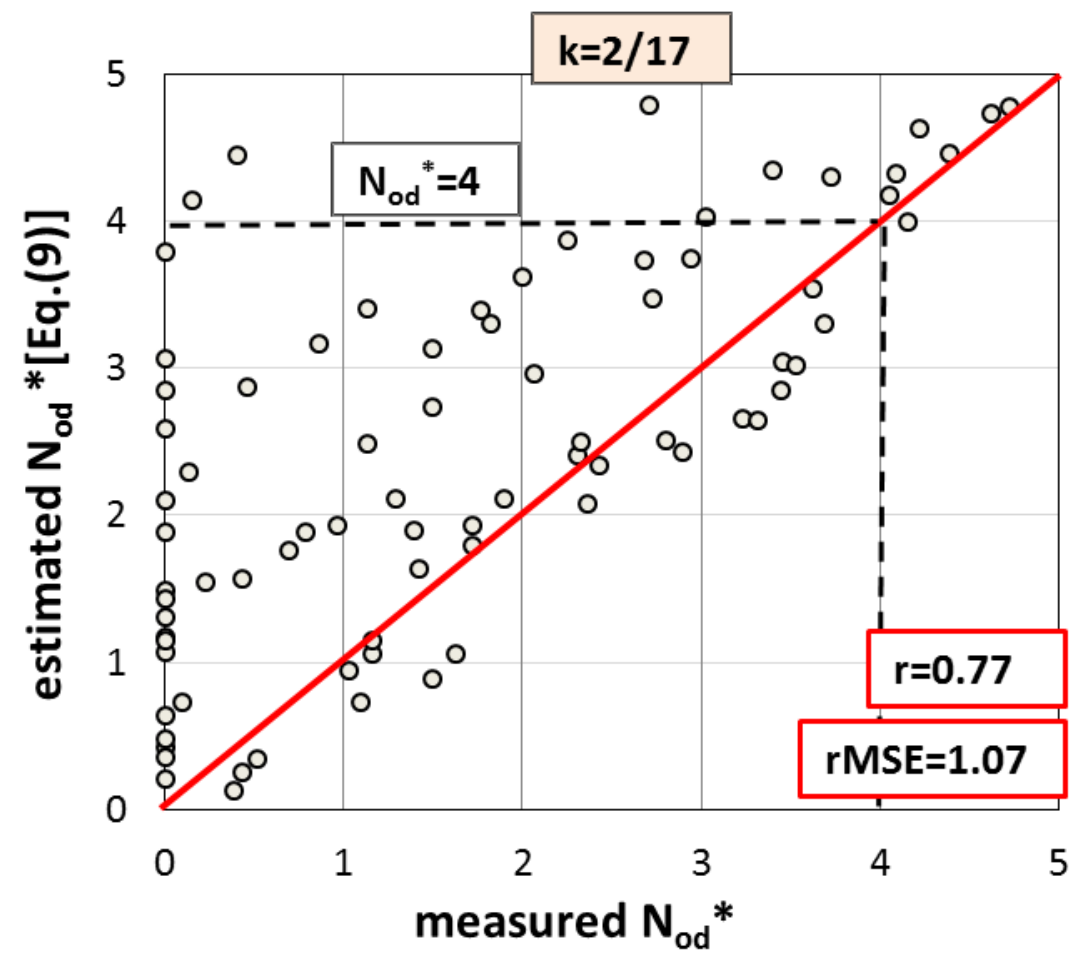

Fig. 15. Comparison of the $N_{o d}{ }^{*}$ measured in tests and that given by Eq. (9) using $k=$ $2 / 17$ rather then $k=0.4$. 
Thus, the parameter $k$ depends on the test conditions. The divergence between $k=2 / 17$ and 0.4 highlights the distinct performance of the toe berm when dealing with plunging waves breaking on a steep sea bottom $(m=1 / 10)$ combined with very shallow waters (as seen in the case of this study), or when dealing with gentler sea bottoms ( $m=1 / 30$ ) and no severe depth-limited wave breaking (as seen in Van Gent and Van der Werf, 2014). These two cases indicate that rock size and toe berm width should be considered together when designing a rock toe berm.

\section{Summary and Conclusions}

Although the hydraulic stability tests of toe berms reported in the literature consider different bottom slopes, $(1 / 50 \leq m \leq 1 / 10)$, toe berm widths $\left(3 D_{n 50} \leq B_{t} \leq 9 D_{n 50}\right)$ and toe berm thicknesses $\left(2 D_{n 50} \leq t_{t} \leq 8.8 D_{n 50}\right)$, toe berm geometry is usually not taken as an explicative parameter of the toe berm damage. Only Van Gent and Van der Werf (2014) explicitly considered the influence of toe berm width $\left(B_{t}=n D_{n 50}\right)$ on toe berm stability. When considering wide toe berms $(n>3)$, common toe berm damage values $\left(0.5 \leq N_{\text {od }}\right.$ s4.0) cannot be directly applied since more rock displacements are required to significantly damage wider toe berms.

This study proposes two new concepts to better characterize the hydraulic stability of wide toe berms $(3<n \leq 12)$ : nominal and sacrificial toe berms. Two areas were distinguished for the toe berm: (1) the most shoreward area of the toe berm (nominal toe berm, $n=3$ ) which supports the armor layer and (2) the most seaward area (sacrificial toe berm) which protects the nominal toe berm. New physical tests were carried out at LPC-UPV with toe berms of different rock sizes $\left(D_{n 50}(\mathrm{~cm})=3.04,3.99\right.$ and 5.12$)$ and toe 
berm widths ( $n=3,5$ and 12). Tests were conducted with a $m=1 / 10$ bottom slope and a SWL close to the top of the berm $\left(1.5 \leq h_{s s} / D_{n 50} \leq 2.6\right)$. The toe berm damage was measured after each test considering: (1) the total toe berm damage $\left(N_{o d}\right)$, and (2) the damage to the nominal toe berm $\left(N_{o d} *\right)$. For wider toe berms $(n>3), N_{o d} *$ turned out to be a better descriptor of toe berm damage; $N_{o d}{ }^{*}$ decreased when increasing the toe berm width $(n)$. When using $N_{o d}{ }^{*}$, recommended design values of conventional toe berm damage can be directly used $\left(0 \leq N_{o d}{ }^{*} \leq 4\right)$.

Given an acceptable level of damage to the nominal toe berm $\left(N_{o d}{ }^{*}\right)$ as a design condition, it is possible to significantly reduce the rock size $\left(D_{n 50}\right)$ by increasing the toe berm width $(n)$ according to Eq. (8). For steep sea bottoms $(m=1 / 10)$ and shallow waters, this reduction in rock size showed an inverse 0.4-power relationship with the relative toe berm width. Using the formula given by Van Gent and Van der Werf (2014) with a gentle bottom slope $m=1 / 30$ and a toe berm thickness $t_{t}=2 D_{n 50}$, the reduction in rock size also followed Eq. (8) but showed an inverse 2/17-power relationship with the toe berm width. Thus, the shape parameter $k=2 / 17$ and 0.4 given in Eq. (8) depends on the water depth and the sea bottom slope existing at the construction site, and it determines the breaking type and the wave impact affecting the toe berm.

To design toe berms placed on $m=1 / 10$ bottom slopes, the rock size reduction may be especially important when the wave conditions are so adverse that it is not possible to find the required rock sizes at the construction site. Thus, the proposed method can be used in these cases for the design of rock toe berms within the ranges $m=1 / 10,3 D_{n 50} \leq$ $B_{t} \leq 12 D_{n 50}, t_{t}=2 D_{n 50}, 1.5 \leq h_{s s} / D_{n 50} \leq 2.6,0.02 \leq \mathrm{s}_{0 p} \leq 0.07,0.4 \leq h_{s s} / H_{s 0} \leq 1.0$ and $0 \leq N_{o d}{ }^{*} \leq 4$. The validity is limited to water depths close to the crest of the toe berm. Further 
research is required to examine the transition area from shallow waters with $m=1 / 10$ analyzed in this study, and the deeper waters and milder bottom slope tested by Van Gent and Van der Werf (2014). Also the effect of other slope angles and toe thicknesses should be investigated.

In shallow waters combined with steep sea bottoms $(m=1 / 10)$, when using sacrificial toe berms, it is convenient to regularly monitor the toe berm. After severe storms, the sacrificial toe berm may be partially washed away and additional dumping of rocks at the toe may be necessary to continue providing full support to the armor layer.

\section{$\underline{\text { References }}$}

Baart, S., Ebbens, R., Nammuni-Krohn, J., Verhagen, H.J., 2010. Toe rock stability for rubble mound breakwaters. Proceedings $32^{\text {nd }}$ International Conference on Coastal Engineering, World Scientific, Shanghai, 3005-3017.

Besley, P., Denechere, M., 2009. Single Layer Armour Systems - Toe, Crest and Roundheads details. Proceedings of Coasts, Marine Structures and Breakwaters 2009 Conference.

Burchart, H.F., Liu, Z., 1995. Rubble Mound Breakwater Failure Modes. Proceedings Final Workshop: Rubble mound failure modes, Sorrento, Italy.

CIRIA, CUR, CETMEF, 2007. The Rock Manual. The Use of Rock in Hydraulic Engineering ( $2^{\text {nd }}$ edition). C683, CIRIA, London.

Ebbens, R.E., 2009. Toe Structures of Rubble Mound Breakwaters. Stability in Depth Limited Conditions. M.Sc. thesis Delft. Delft University of Technology, Delft. 
Figueres, M., Medina, J.R., 2004. Estimation of incident and reflected waves using a fully non-linear wave model. Proceedings $29^{\text {th }}$ International Conference on Coastal Engineering, World Scientific, Singapore, 594-603.

Gerding, E., 1993. Toe Structure Stability of Rubble Mound Breakwaters. M.Sc. thesis Delft and Delft Hydraulics Report H1874. Delft University of Technology, Delft.

Goda, Y., 2000. Random seas and design of maritime structures (2 ${ }^{\text {nd }}$ Edition). World Scientific Publishing, Singapore, ISBN 981-02-3256-X.

Herrera, M.P., Medina, J.R., 2015. Toe berm design for very shallow waters on steep sea bottoms. Coastal Engineering, 103, 67-77.

Hovestad, M., 2005. Breakwaters on steep foreshores: the influence of foreshore steepness on armour stability. M.Sc. thesis Delft. Delft University of Technology, Delft.

Lamberti, A., 1994. Preliminary results on main-armour toe-berm interaction. RMBFM 3rd workshop-DH, De Voorst, The Netherlands.

Muttray, M., 2013. A pragmatic approach to rock toe stability. Coastal Engineering, 82, $56-63$.

USACE, 2006. Coastal Engineering Manual. Engineer Manual 1110-2-1100, U.S. Army Corps of Engineers, Washington, D.C. (in 6 volumes).

Van der Meer, J.W., 1998. Geometrical Design of Coastal Structures. Pilarczyk, K.W. (Ed.), Seawalls, Dikes and Revetments. Balkema, Rotterdam.

Van Gent, M.R.A., Van der Werf, I.M., 2014. Rock toe stability of rubble mound breakwaters. Coastal Engineering, 83, 166-176. 